\title{
Conscientização: dimensões pedagógicas
}

Bruno Botelho Costa

Mestrando em Educação (Unicamp) e bolsista da FAPESP

\section{Resumo}

Este artigo aborda três dimensões pedagógicas do conceito de conscientização no pensamento de Paulo Freire. Procuramos investigar a relação entre a formação da consciência e a caracterização do sujeito em Freire, adentrando o sentido político do agir coletivo e a relevância da linguagem enquanto mediadora de práticas pedagógicas. Subsidiamos esta discussão com apontamentos de Freire e demais colaboradores, na esperança de contribuir para o aprofundamento deste conceito e de possíveis intersecções dele decorrentes.

Palavras-chave: conscientização; educação; Paulo Freire.

\begin{abstract}
This article approaches three pedagogical dimensions of the concept of "conscientization" in Paulo Freire thought. We try to investigate the relation between the forming of conscience and the characterization of the subject in Freire, entering the political sense of collective acting and the relevance of language as a mediator of pedagogical practices. We subsidize this discussion with appointments from Freire and other collaborators, hoping to contribute to the deepening on this concept and its possible intersections that from it result.
\end{abstract}

Keywords: “conscientization”; education; Paulo Freire. 


\section{Introdução}

$\mathrm{O}$ conceito de conscientização em Paulo Freire guarda propriedades que influenciaram toda a sua metodologia, além de sua relevância filosófica para a sua visão de educação e teoria do conhecimento. Este conceito, embora já se encontrasse presente em Educação como Prática de Liberdade, remete a influências intelectuais anteriores com as quais Freire dialogava. Em Conscientização - teoria e prática, o autor comenta o equívoco comum dos meios educacionais de considerá-lo autor do termo, quando este tivera, na verdade, o seu nascedouro nos círculos do ISEB (antigo Instituto Superior de Estudos Brasileiros), entre as teorizações de Álvaro Vieira Pinto e Alberto Guerreiro Ramos (Freire, 1980). Estes pensadores teriam contribuído preponderantemente para conceber tanto a matiz vocabular do termo quanto o seu embasamento conceitual. Sem prejuízo das partes, porém, podemos dizer que Freire alastrou este conceito por intermédio de suas obras, também dando a ele suas considerações e sua verve, de modo que hoje, podemos afirmar tranqüilamente que a divulgação e socialização do termo ocorreram juntamente com seu enriquecimento de conteúdo, através do aprofundamento da discussão teórica e da garimpagem de apontamentos práticos realizados pelo educador. Freire não só levou a conscientização à educação, como também a transformou na égide de uma teoria da educação inovadora e original. Dos campos especulativos e acadêmicos do ISEB, o conceito veio a ter com o povo, mediante o processo dialógico da pedagogia de chão, do processo educacional criador que foi e é a experiência freiriana. Este trabalho pretende discutir, portanto, a partir deste conceito, três dimensões pedagógicas da conscientização do sujeito que são se revelam predominantes em sua caracterização oferecida por Freire, além de permitirem mediações com outros conceitos e problemáticas abordadas pelo mesmo. Inicialmente, tratemos do que caracteriza, para a aprendizagem do individuo, o processo de conscientização. Tratemos também do sentido político e social que ele possui, e, de que modo, a reflexão de Freire transcende barreiras de nossa formação intelectual, muitas vezes circunscrita 
às referências vindas dos "países desenvolvidos" ou do "Primeiro Mundo". Faremos algumas considerações sobre as matizes teóricas usadas por Freire e experimentaremos olhar para a relação entre conscientização e linguagem, procurando ver como esta complementa o processo de aprendizagem dentro da perspectiva freiriana e permite compreender a relação histórica do homem com a natureza e seu sentido cultural. Por fim, encerraremos este artigo perguntando-nos a respeito das mudanças e desafios históricos apresentados aos homens no seu debruçar e agir sobre o mundo e suas contradições; em que medida o contato com a realidade e o outro pode servir de alicerce para uma prática inovadora das relações humanas e, neste sentido, criar espaços diferenciados onde as problemáticas do homem podem ser discutidas e re-significadas autonomamente no campo educacional, sem delimitações externas às suas necessidade e à criticidade de sua consciência?

Primeira dimensão: o processo de desenvolvimento da tomada de consciência

Segundo Freire, a conscientização é um processo de desenvolvimento crítico da tomada de consciência, em que a realidade pode ser des-velada, atingindo-se a sua essência fenomênica (Freire, 1980, p. 26). Através dela, pode-se estar "à frente da realidade", em uma postura de contato e admiração através da percepção autônoma e criticizada, indo além da consciência mágica. O autor descreve este processo de maneira esmiuçada, onde cada passo dado é singular para o surgimento de uma consciência crítica.

Para o autor: "A conscientização é isto: tomar posse da realidade; por esta razão, e por causa da radicalização utópica que a informa, é um afastamento da realidade." (Freire, 1980, p. 29). Este afastamento é também um processo de desmitificação, que permite ao sujeito interpretar e ver a realidade com algo que se apresenta a ele através de suas formas de codificação; um momento onde ele encontra nas imagens "externas" um elo com sigo próprio e cria um significado seu para esta realidade. Cada 
momento marca uma etapa no processo de significação, permitindo que a linguagem apareça por detrás da codificação, permitindo a leitura do mundo. Para descodificar os signos que estão na linguagem, a conjunção de ação e reflexão devem atuar, ambos, em unidade dialética, pois sem que estejam juntas e interligadas, a consciência do sujeito não consegue associar-se a sua prática, ficando destoante uma com a outra. Ir além desta diferença entre um modo de refletir e outro de agir, pode-se assim dizer, é a finalidade da conscientização.

No entanto, para que este processo abranja as diferentes formas de interação do sujeito com o real é preciso que ele abarque diferentes formas de linguagem e codificação. Assim, não convém que o professor se atenha, para análise do professor de aprendizagem, a um conjunto pré-estabelecido de formas aceitáveis de expressão do sujeito, pois os "retornos" do aluno ao professor devem partir de "respostas" formuladas pelo aluno às provocações do professor. Tais respostas representam não apenas formas de descodificação da realidade por parte dos alunos, mas, igualmente, novas codificações com as quais os alunos compreendem a linguagem da didática problematizadora e dos seus significados. Por isso, para que se dê o processo de conscientização, é da maior importância o entendimento e o reconhecimento das diferentes formas de linguagem utilizadas pelo aluno, tanto na sua expressão escrita quanto na sua forma pronunciada, dialogada.

Nisto Freire difere de algumas concepções conservadoras dentro da Educação, para as quais o contato com a codificação escrita e a memorização dos significados de seus respectivos conteúdos é compreendido como metodologicamente e conceitualmente suficientes para que o aluno empreenda sua aprendizagem. Não há, para estas concepções conservadoras, necessidade que aluno ou professor discutam, problematizem e gerem opiniões a respeito dos assuntos abordados em sala. Não há, em última instância, a necessidade de que estes conteúdos possam se transformar em conhecimento para professores e alunos, pois o "conhecimento" dos mesmos reside apenas nas fórmulas bancárias que os transmitem. Não há, tanto para o professor como para o aluno, perspectiva de mediação entre o sujeito e o objeto de seu conhecimento. 
Como se vê, na conscientização dos homens a respeito do objeto de seu conhecimento (objeto este que configura, em última instância, o seu mundo) as apropriações do processo de aprendizagem não se dão exclusivamente por parte dos alunos. O educar, para Freire, é sempre um ajudar o aluno a se educar, uma tomada de ação que permite e tem por objetivo uma tomada de consciência por parte de ambos, formando assim uma relação dialógica que concilia os papéis que ambos exercem e que, tradicionalmente, ao longo da história da educação, foram compartimentalizados em dois pólos contraditórios: educador e educando. Nesta nova relação, educador e educando tornam-se educador-educando, o que representa, em síntese, a criação por ambos de uma mediação mútua do conhecimento, entendendo que, embora de maneiras diferentes, ambos ensinam e aprendem. Se há da parte do professor a necessidade de dispor conteúdos, de discuti-los de forma coletiva, haverá também, por conseguinte, uma maior abrangência no alcance da reflexão, da discussão e do processo educacional como um todo. Não se trata de negar ou se ausentar da experiência e do acúmulo que ele traz em sua caminhada profissional, mas de entender que esta bagagem é uma ferramenta dentre outras no universo de utensílios educacionais que ele e o aluno podem utilizar no processo educacional.

\section{Segunda dimensão: a formação do sujeito histórico e político}

No que tange à formação teórica de Freire, nota-se aqui a influência de abordagens fenomenológicas, influenciadas pelo existencialismo e pelo personalismo, correntes com a quais o autor deve contato mediante a incidência isebiana, na transição da década de 1950 para a de 1960. Entretanto, a forma como Freire apropriou-se dos termos, conceitos e discussões destas escolas, trouxe consigo, devido à influência dos círculos católicos de esquerda, o seu olhar voltado para as problemáticas sociais de um país subdesenvolvido, à margem do Primeiro Mundo, colocado à periferia. Percebe-se isto já nas primeiras experiências pedagógicas e reflexões de Freire no Brasil, em que sua pedagogia chegou ao chão do nordeste interiorano, tocando a vida dos trabalhadores que lá residiam. Esta 
disposição tornou-se, ao longo da sua trajetória como educador, um peso ainda mais global da perspectiva dos oprimidos, ganhando cada vez maior abrangência e aprofundamento político, remetendo-se marcadamente à América Latina. Como nos diz Martha Bardaro:

Nossa educação imitou a americana, nossa filosofia repetiu constantemente os pensadores franceses, belgas, alemães. [...] Freire não negou esta filosofia. Ao contrário, reconheceu muitos dos seus elementos positivos, como os reconhece também em outras vertentes de pensamento (Marx, Fanon, Memmi). Mas repensa-os a partir da periferia. Concretamente, a partir da América Latina. (Bardaro, In: Novoa, 1981, p. 54)

Freire dá, às suas leituras filosóficas, outros contornos, distintos das interpretações européias. Ele tece um caminho desde discussões conceituais familiarizadas pela filosofia e pelas escolas com as quais discute (o homem, teorias do conhecimento, a outro, etc.) até retratos da vida dos seus alunos e, juntamente com isso, faz uma análise social e política do contexto histórico em que estes vivem.

Neste sentido, a conscientização permite e é condição para o alcance da dimensão política do indivíduo, uma vez que para Freire, a real disposição do agir político (necessariamente coletivo) tem que surgir da experiência e assentimento individuais - uma conscientização crítica e própria do sujeito. Isso atinge também - e com toda a importância - a sua visão de si como homem. Não é possível pensar a conscientização sem esta direção: a reflexão de si em meio à realidade que, com a descodificações do estágio mágico (consciência ingênua), passa a ser reconhecidamente própria do indivíduo em seu sentido político e existencial. Não se trata de uma visão solipsista. Trata-se de identificação, de uma ligação do homem com o mundo, uma relação homem-mundo.

Assim, ao sujeito torna-se possível reconhecer a si mesmo não só no mundo, mas também no outro (o outro também está no mundo), pois ao reconhecer a realidade que se configura a despeito de si e, ainda sim, reconhecer-se nesta mesma realidade, o sujeito, o homem vê no outro tudo aquilo pelo ele a também passa e se reconhece. Vê seus sentimentos, suas 
visões de mundo, suas manifestações culturais, e, talvez o mais relevante, não o faz de forma estanque ou padronizada, mas de modo livre e vivo, próprio do re-conhecer. Este reconhecimento é uma transformação na consciência do sujeito, onde ele responde de modo autêntico ao mundo, compreendendo-o segundo sua interpretação. Segundo Freire, o espaço onde o homem se faz sujeito, na afronta da realidade contrária às suas expectativas, é também onde ele pode responder de modo original aos seus desafios. Esta transformação no modo de pensar e agir, muda tanto o meio onde o homem vive como o próprio homem (Freire, 1980, p. 37)

Há que termos em mente que esta compreensão significa, em níveis práticos, que a socialização do debate entre os alunos de Freire representa, sempre e de imediato, a tomada de ação dos mesmos no sentido de transformarem a sua realidade, pois nisto reside o ponto central de sua compreensão do agir política e sua inseparável vinculação ao diálogo. Em Educação como Prática de Liberdade, ao falar da transitividade da consciência do homem frente à realidade em transformação, o educador ressalta a importância do diálogo para formar o sujeito histórico.

Esta transitividade da consciência permeabiliza o homem. Leva-o a vencer o seu incompromisso para com a existência, característico da consciência intransitiva e o compromete quase totalmente. Por isso mesmo que, existir, é um conceito dinâmico. Implica numa dialogação eterna do homem com o homem. Do homem com o mundo. Do homem com o seu Criador. É essa dialogação do homem sobre o mundo e com o mundo mesmo, sobre os desafios e problemas, que o faz histórico. (Freire, 1979, p. 60)

O diálogo é uma reflexão dos homens sobre sua própria existência, onde eles encontram o outro, tanto no sentido do companheirismo entre os homens, como em sua relação com o transcendente (sua ligação com Deus). Não há como dialogar com o outro se não houver diálogo do homem consigo próprio. Segundo Bortolozo, “O diálogo, dessa forma, põe-se como o modo mais autêntico da relação inter-humana. Enfim, ele é o modo constitutivo do existir humano autêntico no mundo." (Bortolozo, 1993, p. 37). Nele o homem apreende a transitividade do seu tempo, dispondo-se a 
participar de sua época histórica. No encontro dialógico em comunhão com o outro, ele vai reconhecendo a necessidade do agir coletivo e sua dimensão política por excelência.

Em Pedagogia do Oprimido, o autor aprofunda sua análise sobre as implicações políticas e conscientizadoras do diálogo, voltando-se à questão da opressão pelo silenciamento e o tolhimento à pronúncia da palavra oprimida. Partindo da dimensão prática e transformadora que o diálogo, ele recompõe a noção da palavra como práxis, como um fazer conjugado entre ação e reflexão. Sobre este sentido da palavra, Freire diz que:

Esta busca nos leva a surpreender, nela, duas dimensões; ação e reflexão, de tal forma solidárias, em uma interação tão radical que, sacrificada, ainda que em parte, uma delas, se ressente, imediatamente, a outra. Não há palavra verdadeira que não seja práxis. Daí, que dizer a palavra verdadeira seja transformar o mundo. (Freire, 1983, p. 91)

Considerando a palavra uma forma de ação no mundo, Freire faz uma releitura da relação teórico-prática do sujeito e seu agir político. Ele compreende a relação entre o nível de consciência do sujeito e seu agir concreto como circunscritos pela temporalidade, elo da transcendência do homem no mundo. Esta releitura serve de fundamento para sua concepção de história, noção cujos alicerces ele encontrou em leituras existencialistas e fenomenológicas (Bortolozo, 1993). Entretanto, isso não o impediu de aproximar-se, particularmente durante suas experiências no Chile, da concepção historicista de Marx e de outros autores marxistas. Sua obra magna, Pedagogia do Oprimido, testemunha este diálogo, aprofundando as discussões sobre a relevância desta abordagem teórica para a libertação dos homens.

Para Freire, a história é o processo de tomada de consciência mediante as condições de época histórica, na qual o homem participa e na qual se emerge. Nela, apresenta-se como desafio do seu tempo tudo aquilo com o que, identificando-se, o homem visa modificar. Não há, portanto, como entender este conceito sem que a conscientização seja o seu pano de fundo. Assim como não é possível, segundo o autor, buscar a participação 
do homem na história sem compreender o papel fundamental que possui, neste processo, a pronúncia de sua palavra e nem o seu engajamento na libertação dos homens sem com eles se solidarizar, sem possuir um profundo amor e fé nos homens e na sua capacidade de transformar o mundo e a si mesmos.

\section{Terceira dimensão: sectarização, radicalização e implicações pedagógicas da linguagem}

A crença autêntica no propósito de libertação dos homens deve balizar as relações que eles empreendem no processo de conscientização. Para tanto, é fundamental ter em mente o "caráter eminentemente pedagógico da revolução" (Freire, 1983, p. 59), pois somente assim é possível que os homens realizem sua vocação ontológica de ser mais. Não é possível conivência da parte dos educadores comprometidos com esse propósito para com as práticas sectárias de transferência de concepções estranhas ao processo de elaboração autônoma do conhecimento. Desnecessário dizer que independe, para efeitos desta crítica, se os promotores destas práticas afirmem defender a libertação. Em sua prática concreta eles estão se contradizendo.

Talvez por isso Freire fosse tão presente ao mencionar, dentro do cenário mundial de seu tempo, o rechaço à política de direita, "sectária de nascimento" como as contribuições históricas que os movimentos políticos de esquerda realizavam; sem, no entanto, poupar de sua crítica, a presença de reacionarismos dentro da formação ideológica de alguns dos mesmos, onde a massificação era empreendida pela suposta "liderança revolucionária" a título de melhor cuidar dos aspectos subjetivos do homem “após revolução estar consolidada".

A separação dos momentos históricos pode levar os educadores a delimitar "prioridades" de método e abordagem de conteúdos que acabem por tolher o aprendizado dos alunos e ação cultural dos mesmos. Levando em conta as considerações de Freire sobre a cultura, para quem ele "é todo resultado de atividade humana, do esforço criador e recriador do homem, do 
seu trabalho por transformar e estabelecer relações de diálogo entre os homens" (Freire, 1980, p. 39), percebe-se que nesta questão não se pode, legitimamente, a despeito de características do momento histórico, restringir a participação dos homens na elaboração do seu saber e conhecimento. A questão do método não pode ser entendida como "o caminho das pedras". Observemos uma citação de Freire retirada de um trabalho - inconcluído na época - de Álvaro Vieira Pinto:

O método é, na verdade, a forma exterior e materializada em atos, que assume a propriedade fundamental da consciência: a sua intencionalidade. O próprio da consciência é estar com o mundo e este procedimento é permanente e irrecusável. Portanto, a consciência é, em sua essência, um 'caminho para' algo que não é ela, que está fora dela, que a circunda e que ela apreende por sua capacidade ideativa. Por definição, continua o professor brasileiro, a consciência é, pois, método, entendido este no seu sentido de máxima generalidade. Tal é a raiz do método, assim como tal é a essência da consciência, que só existe enquanto faculdade abstrata e metódica. (Freire, 1983. p. 61)

Partindo desta concepção, temos claro que o método não pode anteceder a consciência, pois, assim, incorre-se no erro de anteceder normas de funcionamento do processo educacional e cognitivo dos educandos. É esta a perspectiva pelo educador radical, aquele que busca na raiz das problemáticas do homem com seu mundo as respostas aos seus desafios. É durante esta busca que se processam as formas de aprender e onde os modos de agir e de "retornar" aos sujeitos cognocentes, aos educadores-educandos, um conhecimento inédito pode, autenticamente, acontecer. Assim como a prática da palavra, mudando a forma e o ponto de partida de onde esta se pronuncia é capaz de promover o respeito e o reconhecimento do outro e ser instrumento no transformar o mundo, a linguagem, juntamente com ela, exerce esse sentido de aproximação do sujeito com a realidade. Se, em um primeiro momento, ele se afasta desta, para ressignificá-la, ele o faz no intuito de retomá-la, denunciá-la e anunciar, nela, o novo possível, fruto do conhecimento adquirido nas relações de diálogo que se estabeleceram. 
Estas mudanças implicam em uma mudança não de visão dos homens, do mundo e de seu processo pedagógico, mas também da linguagem criada e empregada tendo por fim a conscientização dos mesmos. Segundo Freire:

Mudar a linguagem faz parte do processo de mudar o mundo: não é preciso esperar que o mundo mude para mudar a linguagem. A incontinência verbal, o palavreado irresponsável são um equívoco, não tem nada a ver com uma compreensão correta da luta. Suas conseqüências apenas retardam as mudanças necessárias. (Freire, 1979, p. 57)

A mudança da linguagem não é apenas a transformação na forma de expressar o mundo, mas também na comunicação que surge deste processo. Através da linguagem, esta comunicação inova as relações entre os homens e sua existência implica, desde já, em uma mudança prática na vida e no mundo dos mesmos. Dentre as possibilidades de transformação inauguradas pela mudança da linguagem está o surgimento de novas formas de representação do sujeito e do mundo. No momento em que os homens iniciam, através do processo pedagógico crítico e conscientizador, uma mudança em suas visões de mundo, eles iniciam, também, uma mudança nas formas de representar o mundo, de trazer a tona, de explicar, de exprimir em sínteses estas visões de mundo. Recriam, deste modo, a linguagem que utilizam, passando a exercê-la não de forma bancária, depositária, mas sim, de modo libertador, emancipador. Não é possível que, transformando suas visões de mundo, não transformem também sua linguagem. Assim, se existir, no processo pedagógico, não apenas uma simples troca de conteúdos, uma substituições de referenciais, que, por si, apenas modifica o teor da cartilha a ser seguida, mas ao invés disso, uma genuína construção autônoma do conhecimento, onde o educando se torne sujeito-cognocente, existirá, necessariamente, uma transformação nas representações que o mesmo fará do mundo e de si mesmo, resultando em formas igualmente diferenciadas de expressar estas representações. Pode-se dizer que a comunicação já é, enquanto elemento constituinte da linguagem libertadora, uma, senão a principal, das diferenciadas formas pelas quais os 
homens passam a representar seu mundo e vida.

A transformação das representações do mundo e o conseqüente surgimento de novas práticas que correspondem, em termos de mediação, à perspectiva ressignicada dos educandos, contribuem para provocar neles uma nova abrangência do seu conhecimento. Por terem constituindo um novo saber, passam a olhar a realidade de outra maneira, a se apropriarem dela de forma mais livre, podendo recorrer ao conhecimento construído com a segurança de ter, ele próprio, realizado o trabalho de sua significação. Este alargamento da abrangência de seu conhecimento não se modifica, nesta provocação, somente em termos quantitativos, mas, sobretudo, em termos qualitativos; resultando este alargamento não na implementação de novas informações na consciência do educando, mas em uma síntese original realizada por ele próprio, onde ele enxerga novas possibilidades de resposta aos desafios que o mundo lhe apresenta. A viabilidade da realização desta possibilidade se dá, particularmente, pelo sentido diferenciado e genuíno que assumem as suas perguntas, ou seja, ela é propriamente resultado de uma nova abordagem sobre as respostas anteriormente dadas às problemáticas do mundo, suas situações-limite, que busca superar os limites destas situações através de um novo horizonte, ainda irrealizado, mas nem por isso menos viável que a concretude a situação atual: este horizonte é o que Freire denomina inéditos-viáveis. E o vislumbre daquilo que se encontra além das "situações-limite", o recorte imediato ao qual ele se encontra preso. O inédito-viável é a representação do desafio histórico que, compreendido pelo homem, motiva o nascimento de sua própria prática.

Tal importância teve a linguagem nos "temas-geradores", onde o "universo temático mínimo" dos círculos de cultura mostrou que a conscientização se faz com pouco, que a simplicidade dos conceitos iniciais poderia gerar diálogos mais aprofundados e também significações mais complexas, a ponto da escrita não parecer mais estranha, do professor doutor não falar mais tão esquisito. A linguagem é também a forma como o homem vê o movimento do mundo como algo na qual ele pode agir, em que ele pode participar e onde sua ação inicia um movimento contrário àquele que faz dele um sujeito aderente à situação concreta. Pode, assim, 
compreender e participar da história e exercer esta participação através da sua cultura, pois a mediação dele com o mundo e com o outro, através da linguagem, dá-lhe uma consciência temporalizada, onde é possível o afastamento e emersão no tempo (criação histórica) e, por conseguinte, a sua ação cultural e não apenas natural.

\section{Conclusão}

Por fim, pode-se dizer que, através destas dimensões pedagógicas, é possível visualizar aquilo que, nos parece, é o projeto fundamental da pedagogia freiriana: conceber a educação como forma de transformação da consciência dos homens através das experiências de ação-reflexão que permitem que, enquanto sujeitos, tomem o mundo por objeto. Este propósito faz com que a configuração do mundo (suas dimensões históricas, políticas e linguiísticas) possa ser encarada como um retrato, também, dos homens; uma vez que estes, necessariamente, existem no mundo e enquanto seres do mundo. Se estes possuem, por vocação ontológica, a disposição para serem sujeitos deste mundo, é porque não apenas o dominam, mas tem a ele se sujeitam em busca de alternativas para transformá-lo. Assim, a conscientização dos homens, enquanto surge deles mesmos, reforça o caráter pedagógico da interação do homem com a realidade que o circunscreve, enxergando a objetividade das dimensões humanas, a concretude do ato empreendido pelo sujeito e a viabilidade de uma nova composição das problemáticas do mundo, tanto no que tange à ressignificação dos desafios por ele apresentados, sendo estes transformados ao longo da práxis libertadora, quanto no que tange ao valor educacional que este processo têm, abrindo novas provocações no sujeito e seu mundo e novas perspectivas para que realize, no mundo e em si mesmo, uma autêntica transformação. 


\section{Referências}

BARDARO, M. Paulo Freire e o Pensamento Existencialista. In: NOVOA, C. Leitura Crítica de Paulo Freire. São Paulo: Loyola, 1981.

BORTOLOZO, M. Incursões pela Concepşão de Subjetividade do Pensamento Pedagógico de Paulo Freire. 1993. 122ff. Dissertação (Mestrado em Educação) - Faculdade de Educação, Universidade Estadual de Campinas, Campinas, 1993.

FREIRE, P. A importância do ato de ler. São Paulo: Cortez, 2001. - Ação Cultural para a Liberdade e outros textos. Rio de Janeiro: Paz e Terra, 1976.

. Conscientização. São Paulo: Moraes, 1980.

. Educação como Prática de Liberdade. Rio de Janeiro: Paz e Terra, 1979.

. Pedagogia da Autonomia. São Paulo: Paz e Terra, 1996.

. Pedagogia do Oprimido. Rio de Janeiro: Paz e Terra, 1983.

OLIVEIRA, R. D. de; DOMINICE, P. Freire: Desvelar. In: NOVOA, C. Leitura Crítica de Paulo Freire. São Paulo: Loyola, 1981. 